\title{
Correction to: Andrew Marvell: A Literary Life
}

\author{
Matthew C. Augustine
}

\section{Correction to:}

Chapter 2 in: M. C. Augustine, Andrew Marvell, Literary Lives, https://doi.org/10.1007/978-3-030-59287-5_2

Chapter 3 in: M. C. Augustine, Andrew Marvell, Literary Lives, https://doi.org/10.1007/978-3-030-59287-5_3

This book was inadvertently published with author name as "Andreae Filiae" in the chapter title of Chapter 2, TOC and on page 48 of Chapter 3 which has been corrected to "Andreae Filius".

\footnotetext{
The updated versions of the chapters can be found at https://doi.org/10.1007/978-3-030-59287-5 https://doi.org/10.1007/978-3-030-59287-5_2 https://doi.org/10.1007/978-3-030-59287-5_3 